\title{
Growth of crypt cell nodules in duodenal mucosa in man during organ culture in vitro
}

\author{
DN CHALLACOMBE, EE WHEELER \\ From the Somerset Children's Research Unit, Musgrove Park Hospital, Taunton, Somerset
}

SUMmaRY Culture of peroral biopsy specimens from duodenal mucosa in vitro for 22 hours using a basic culture medium resulted in the formation of crypt cell nodules. The addition of collagen and serotonin to the culture medium increased the occurrence of the nodules and, invariably, their size. The nodules were situated on the pericryptal basement membrane and contained cells that resembled columnar cells, goblet cells, and endocrine cells. The overall nodular structure suggested that they had been formed by the stimulation of stem cell division at the crypt base, but the factors responsible for this have not as yet been identified. The growth of these nodules may offer opportunities for studying stem cell division and differentiation in small intestinal mucosa in man.

Peroral biopsy specimens from the duodenum were cultured in vitro for 22 hours in this laboratory, using a basic culture medium and the addition of serotonin (5-hydroxytryptamine, 5-HT) and acid soluble rat tail collagen. Serotonin was added because it accelerates the turnover of crypt cells in the rat small intestine, ${ }^{1}$ and collagen has been widely used as a substrate for cell growth and differentiation in tissue culture experiments. ${ }^{2}$ The structure of the nodules was investigated by light and electron microscopy, and possible causes for their formation in duodenal organ cultures were suggested.

\section{Material and methods}

\section{SMALLINTESTINAL BIOPSY}

Peroral mucosal biopsies were obtained from the third or fourth part of the duodenum from 24 adults and three children (age range 1 year 4 months to 92 years) who were being routinely investigated for dyspepsia or failure to thrive, respectively. Biopsies were performed on the adults using a fibreoptic endoscope with biopsy forceps (Olympus GIF 1T) and on the children using a Watson paediatric biopsy capsule. Specimens were received into cold Leibowitz L-15 medium and were taken immediately to the laboratory, where they were flattened serosal surface downwards, using aseptic techniques. The specimens were then divided, and samples for routine histopathology

Accepted for publication 15 August 1985 were immediately fixed in either $10 \%$ buffered formalin or acetified formol sublimate.

ORGAN CULTURE

Specimens of duodenal tissue from each patient wexe placed serosal surface downwards on a stainless stee grid platform positioned at one end of a well in a Lux rectangular culture dish (Flow Laboratories). Two different culture media were used during the study. The first was the basic medium, comprising $6 \mathrm{ml}$ of Trowell's T-8 medium, $2 \mathrm{ml}$ of (National Collection of Type Cultures) 135 medium, $1.5 \mathrm{ml}$ of 309 fetal calf serum (GIBCO), $0.2 \mathrm{ml}$ of L-glutamine $(200 \mathrm{mM})$, $0.05 \mathrm{ml}$ of penicillin and streptomycin $(5000 \mathrm{U}$ of each), $0.025 \mathrm{ml}$ of proprietary and $0.1 \mathrm{ml}$ of HEPES (1M). The second culture medium consisted of $10 \mathrm{ml}$ of the basic medium with the following additions: $10 \mathrm{mg}$ of serotonin creatinine sulphate complex (Sigma), after which the medium was resterilised by millipore filtration and cooled to $4^{\circ} \mathrm{C}$, and $0.1 \mathrm{ml}$ of a $0.5 \%$ rat tail collagen solution (Sigma Type VII) in $17.5 \mathrm{mM}$ glacial acetic acid, which was made up and shaken with the culture medium to prevent the for- $\bar{N}$ mation of gel. Sufficient tissue was available from 14 . of the 27 patients for parallel organ culture experi- $N$ ments to be performed, using both types of culture $\underset{\omega}{\mathbb{N}}$ medium. Of the remaining 13 patients single organ $\sigma$ cultures were performed using only the second culture oo medium. In all experiments the culture medium was warmed to $37^{\circ} \mathrm{C}$, and $2.5 \mathrm{ml}$ was placed in each cul- ?? ture dish. The dish was then covered with a lid 7 (slightly raised to enable gassing to take place) and 
placed in a controlled atmosphere chamber (Bellco Glass Inc), which contained a dish of sterile water to maintain humidity. The chamber was sealed, placed on a rocking apparatus within a $37^{\circ} \mathrm{C}$ incubator, and rocked at $4 \mathrm{rpm}$ in an atmosphere of $95 \%$ oxygen and $5 \%$ carbon dioxide, to enable the underside of the tissue to be alternately exposed to the gas phase and the medium. The duodenal explants were cultured for 22 hours before they were removed and fixed in acetified formol sublimate followed by routine embedding on edge in Paraplast Plus. All specimens were then sectioned at $4 \mu \mathrm{m}$ and stained with haematoxylin and eosin and diastase periodic acid Schiff.

\section{ELECTRON MICROSCOPY}

Specimens of organ culture for electron microscopy were bisected and immediately fixed in 3\% glutaraldehyde in cacodylate buffer and subsequently fixed in osmium tetroxide. After dehydration specimens were embedded flat, serosal surface downwards, in EPON 812 and polymerised at $70^{\circ} \mathrm{C}$. Sections were cut perpendicular to the mucosal surface at $2 \mu \mathrm{m}$, stained with toluidine blue, and examined by light microscopy. Areas of tissue that contained crypt cell nodules were identified and ultrathin sections were cut and stained with uranyl acetate and lead citrate before being examined by electron microscopy.

\section{Results}

Histological sections of duodenal mucosa obtained from all the patients before organ culture had a nor- mal morphological appearance by light microscopy. After organ culture the histological appearances were characterised by a decrease in the height of some villi, a mantle of cellular debris and mucin on the mucosal surface, good preservation of the villous epithelial cells, ${ }^{3}$ and the presence of crypt cell nodules in some sections (Fig. 1). In addition, a monolayer of flattened or cuboidal epithelial cells was occasionally present, which originated from the luminal epithelium at the lateral cut edge of the section and extended below the muscularis mucosae ("epiboly"). Structures like cysts lined with epithelial cells, bifurcating crypts, and necrosing crypts were also occasionally observed.

In the parallel organ culture experiments performed on tissue from 14 patients using the two different media crypt cell nodules were observed by light microscopy in tissue cultured only in the basic medium from four patients and cultured in the basic medium from eight patients with added collagen and serotonin. In culture experiments on tissue from the remaining 13 patients using the basic medium with added collagen and serotonin nodules were present in eight patients, including the three children. Thus nodules were present in tissue specimens from $16(59 \%)$ of the patients cultured in the basic medium with added collagen and serotonin and from four $(29 \%)$ of 14 of the same 27 patients cultured only in the basic medium.

When nodules were present in sections of tissue cultured in medium containing collagen and serotonin they varied in size, shape, and number, and while some were tall, protruding through the crypt neck,

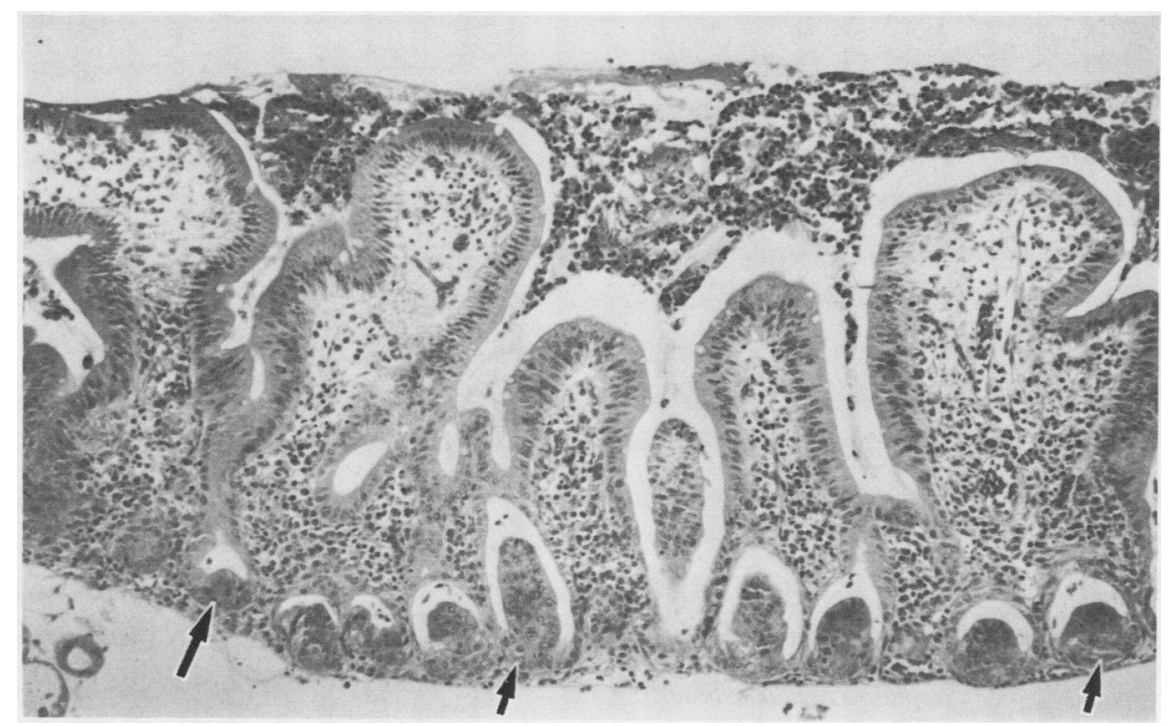

Fig. 1 Organ culture (22 hours) of human duodenal mucosa with added collagen and serotonin, showing crypt-cell nodules. (Haematoxylin and eosin.) $\times 120$. 


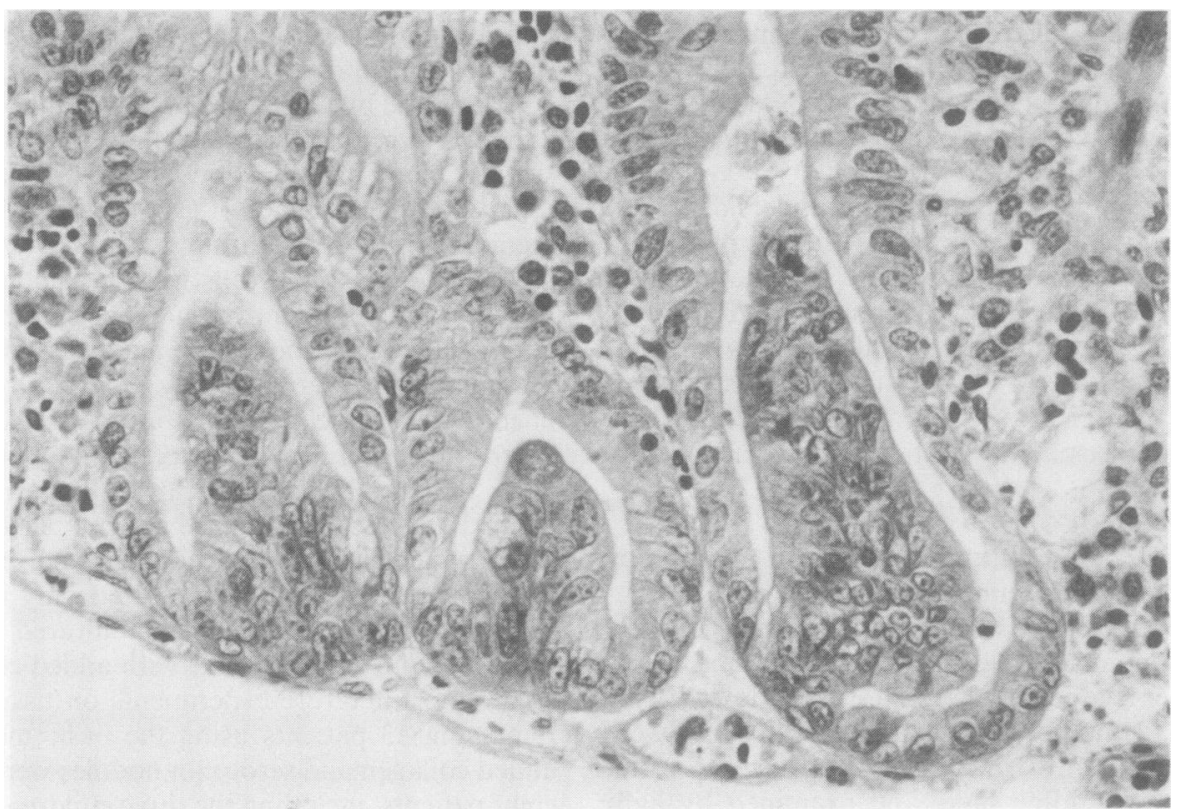

Fig. 2 Higher power view of nodule formation in three crypts. (Haematoxylin and eosin.) $\times 512$.

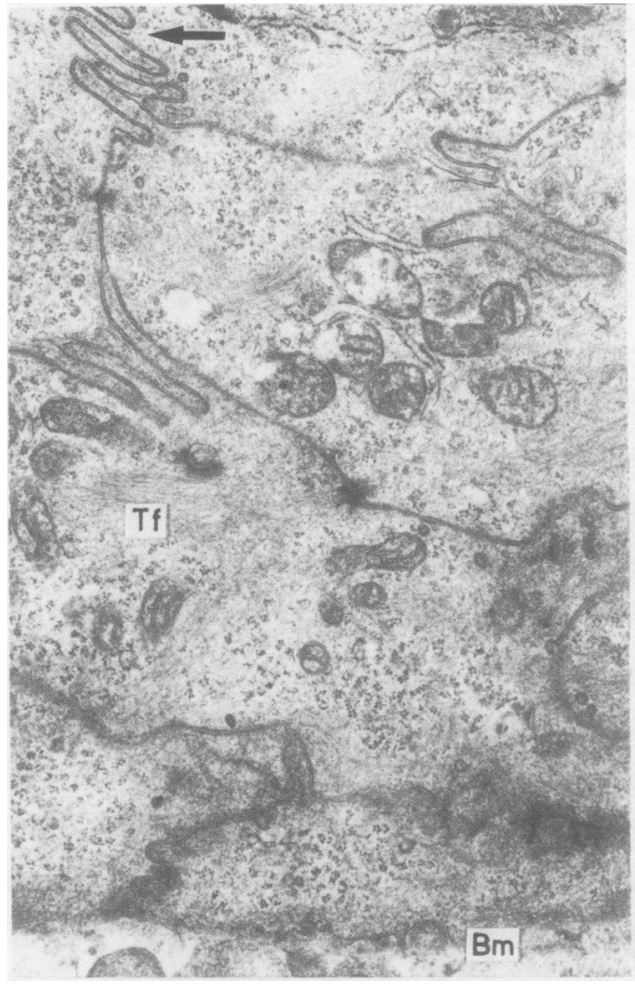

Fig. 3 Complexity of cell cytoplasms at nodule base. $-=$ interdigitating complex, $T f=$ tonofilaments $B m=$ pericryptal basement membrane. Electron micrograph $\times 13300$.

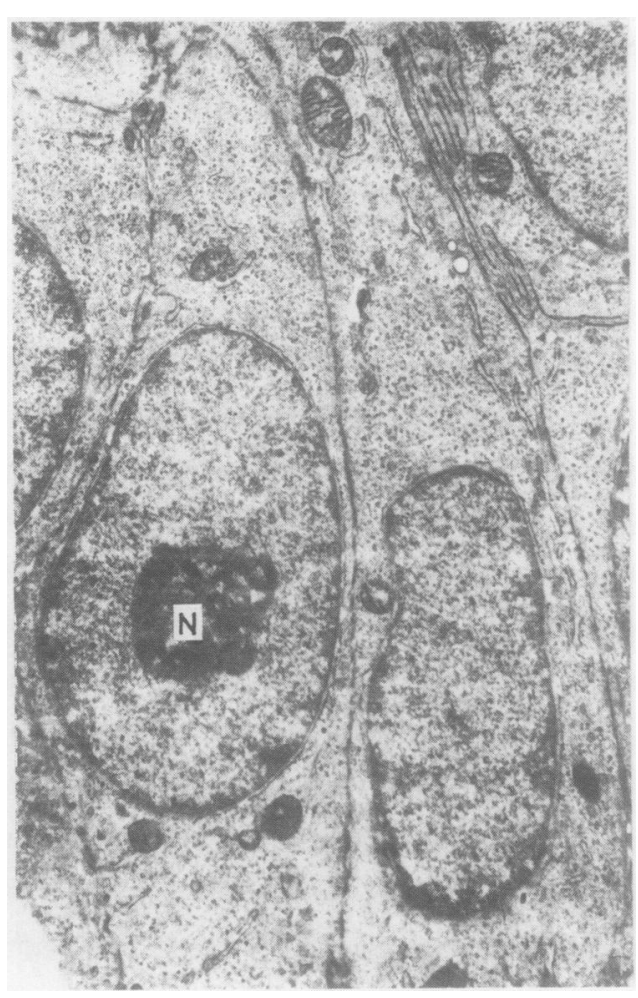

Fig. 4 Stem cells in lower part of nodule. $n=$ reticulated nucleolus. Electron micrograph $\times 9200$. 
others were small and sometimes seemed to be surrounded by the crypt wall. Nodules occurring in samples cultured in the basic medium, however, were small in size and few in number and tended to occur near the edges of the specimen. When serial sections of the nodules were taken and camera lucida drawings of them made they were all shown to occur in a crypt that opened into the gut lumen, and their varied appearances in some sections were due to differences in tissue orientation or to the depth of sectioning. Nodules were usually found in specimens with a thin muscularis mucosae and with very little underlying connective tissue. When greater amounts of underlying connective tissue were present the nodules tended to occur in the lateral parts of the explant. A detailed study of the structure of the nodules by both light and electron microscopy showed that they were closely associated with the pericryptal basement membrane (Fig. 2). In none of the sections examined, however, did the basement membrane extend into any nodule. A complex arrangement of undifferentiated cytoplasm and interdigitating cell membranes containing desmosomes was usually present at the base of the nodule, attached to the basement membrane (Fig. 3). Elongated and polygonal shaped cells were also present at the base of the nodule, containing large oval nuclei and one or more prominent nucleoli, several of which were eosinophilic, reticulated, and sometimes marginated (Fig. 4). Many of these cells were undifferentiated and closely resembled the undifferentiated columnar cells found at the base of normal crypts, which are widely regarded as stem cells. $^{45}$ The cytoplasm of these cells was full of free ribosomes and polyribosomes with a few mitochondria, and some cells contained tonofilaments. At the lateral part of the base of the nodules adjoining the crypt the epithelial cells were often flat and cuboidal with microvilli on their surfaces and were closely associated with the pericryptal basement membrane (Fig. 5). The height of these cells increased further up the crypt until typical columnar cells were observed at the crypt neck (Fig. 2). In the central core of the nodules were cells with more organelles such as mitochondria, Golgi bodies, and rough endoplasmic reticulum. All these cells were closely packed together and their cell membranes were interdigitated (Fig. 6). Some cells within the nodule contained mucous granules within their cytoplasm and endocrine like cells were also present with cytoplasm containing many characteristic granules (Fig. 7).

The proportion of more differentiated to undifferentiated cells varied between the nodules. Most cells on the surface were more differentiated than those at the base and resembled immature columnar cells or false stratified columnar cells in the smaller nodules (Fig. 8) The cytoplasm of these cells

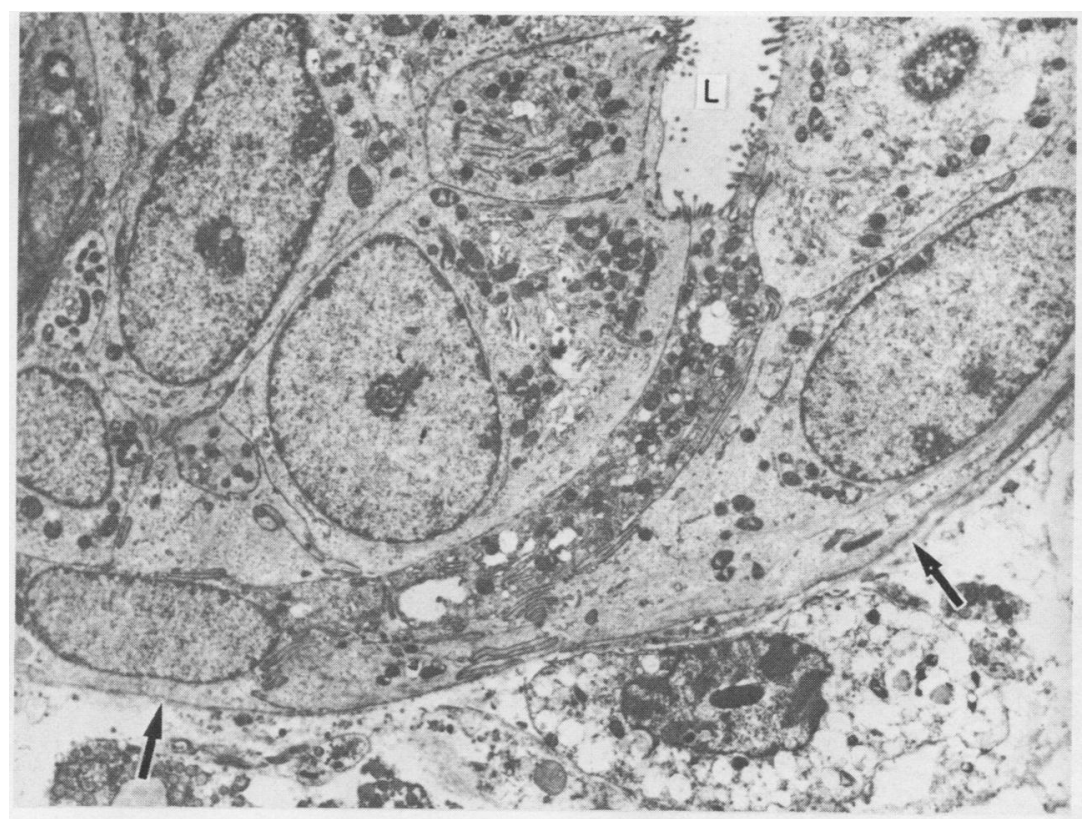

Fig. 5 Margin of nodule with crypt wall. $D=$ pericryptal basement membrane, $L=$ crypt lumen. Electron micrograph $\times 3400$. 


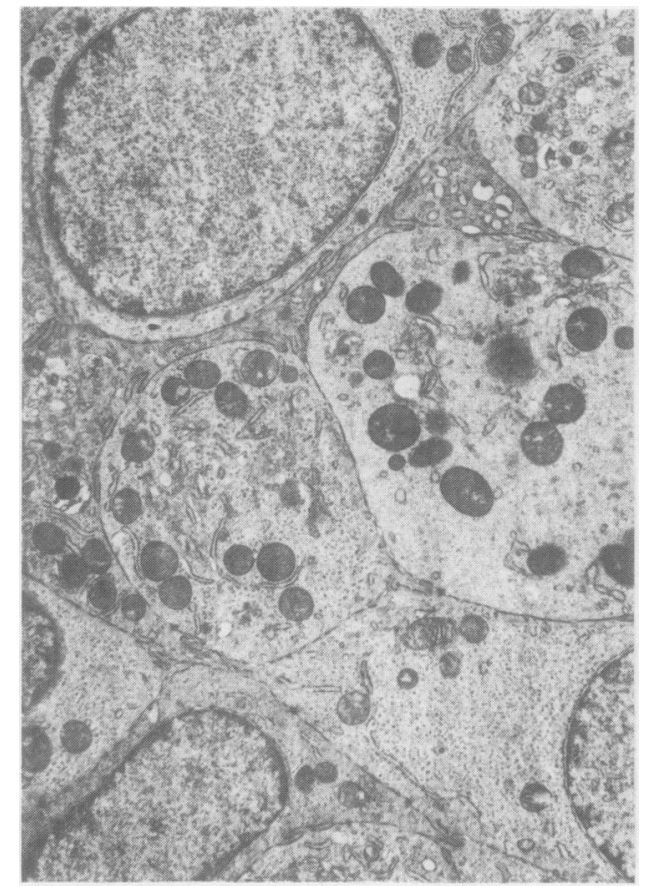

Fig. 6 Centre of nodule showing polygonal shaped cells and increased organelles. Electron micrograph $\times$ 6400.

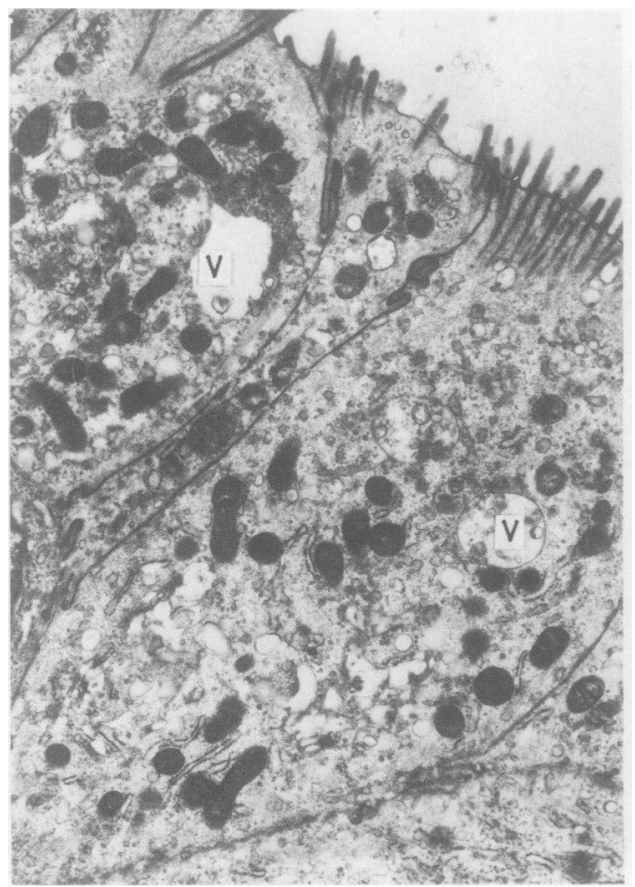

Fig. 8 Immature columnar cells on apex of nodule. $V$ $=$ vacuole. Electron micrograph $\times 8000$.

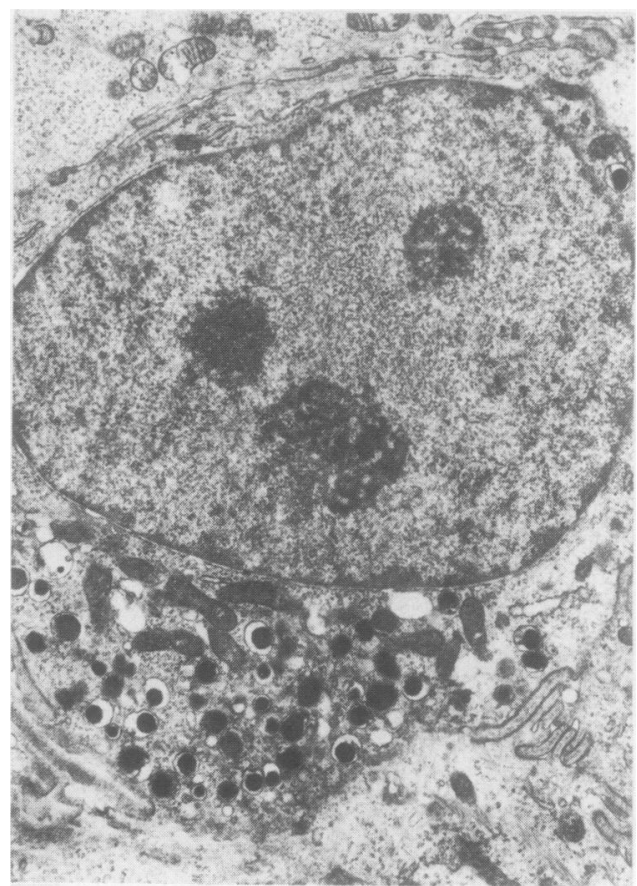

Fig. 7 Endocrine like cell. Electron micrograph $\times$ 8500 .

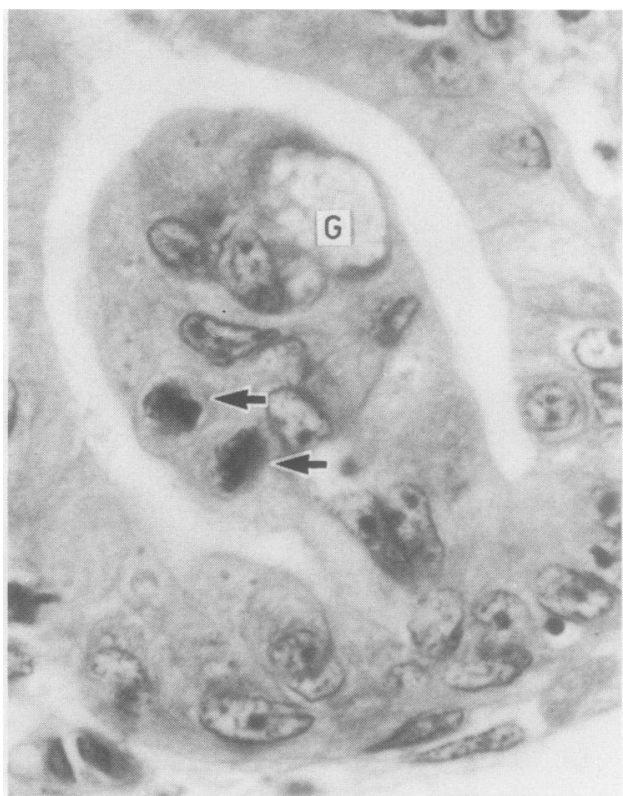

Fig. 9 Nodule containing goblet like cell $(G)$ and mitotic figures ( ). (Haematoxylin and eosin.) $\times$ 1280 
was often vacuolated, and the microvilli were often short and irregular, with long branching root corelets. Sometimes a goblet like cell (Fig. 9) was seen that was full of mucin, positive for periodic acid Schiff, and the surfaces of most nodules were also coated with mucin. Surface epithelial cells seemed to maintain close relations with each other, and tight junctions seemed to be present. Typical Paneth cells were not seen in any of the nodules but were present in neighbouring crypts in which nodules were absent. Mitotic figures were observed only twice in two nodules (within surface epithelial cells) (Fig. 9).

\section{Discussion}

The finding of nodules in the crypts of cultured duodenal explants in man has not, to the best of our knowledge, been described previously. The basal crypt stem cells are thought to give rise to all four cell lines in the epithelium-namely, columnar cells, endocrine cells, goblet cells, and Paneth cells. ${ }^{6}$ Cells resembling columnar cells, goblet cells, and endocrine cells were present within many of the nodules, but Paneth cells have not as yet been positively identified, and their absence requires further study. Hence three of the four cell types in the normal small intestinal epithelium thought to be derived from stem cells were present, suggesting that the growth of these nodules in vitro may be of value in studying the lineage of epithelial cells. The overall nodular structure suggested that certain experimental conditions had stimulated the division of stem cells at the crypt base to produce both epithelial cells within the nodules and epithelial cells lining the crypts. The factors principally responsible for this finding, however, have not as yet been identified. The addition of collagen and serotonin to the basic culture medium seemed to increase the incidence of the nodules and invariably their size; serotonin accelerates the turnover of epithelial cells in the rat small intestine. ${ }^{1}$ The collagen used in this study was predominantly Type I (Miller classification ${ }^{7}$ ) with less than $5 \%$ Type III, and tissue function may have been changed by a change in the relative proportion of these collagens. ${ }^{8}$ Further studies are required to evaluate the contribution of each constituent of the culture medium to the formation of nodules and also the role of other factors in the experiment.

Nodules were more common in tissue in which cleavage had occurred along the muscularis mucosae at biopsy, resulting in the absence of muscle and connective tissue below the mucosa. Stem cell hyperplasia could therefore have arisen in response to the close proximity of stem cells at the crypt base to the culture medium or to the high concentration of oxygen caused by tissue rocking. The growth of tumours in the small intestine in vivo is rare in man. The finding that crypt cell nodules could be grown in the duodenal mucosa in vitro may offer opportunities for studying factors that influence the division and differentiation of stem cells in the small intestine in man.

We thank Drs M Barry, PD Dawkins, AE Adam, and Professor NA Wright for their advice and Dr PD Howdle and Professor MS Losowsky for their assistance with the organ culture technique. We also thank Mrs Eve Sweet for her secretarial help and the members of Burnham-on-Sea and Highbridge Round Table for their generous financial support.

\section{References}

${ }^{1}$ Tutton PJ. The influence of serotonin on crypt cell proliferation in the jejunum of rat. Virchows Arch (Cell Pathol) 1974;16:79-87.

${ }^{2}$ Strom SC, Michalopoulos G. Collagen as a substrate for cell growth and differentiation. In: Cunningham LW, Frederikson DW, eds. Methods in enzymology. New York: Academic Press, 1982:544-55.

${ }^{3}$ Browning TH, Trier JS. Organ culture of mucosal biopsies of human small intestine. $J$ Clin Invest 1969;48:1423-32.

${ }^{4}$ Cheng $\mathrm{H}$, Leblond CP. Origin, differentiation and renewal of the four main epithelial cell types in the mouse small intestine. V. Unitarian theory of the origin of the four epithelial cell types. Am J Anat 1974;141(4):537-61.

${ }^{5}$ Bjerkness $M$, Cheng $H$. The stem-cell zone of the small intestinal epithelium. III Evidence from columnar, enteroendocrine, and mucus cells in the adult mouse. Am J Anat 1981;160(1):77-91.

${ }^{6}$ Leblond CP, Cheng H. Identification of stem cells in the small intestine of the mouse. In: Cairnie AB, Lala PK, Osmond OG, eds. Stem cells of renewing cell populations. New York: Academic Press, 1976:7-31.

${ }^{7}$ Miller EJ. Biochemical characteristics and biological significance of the genetically distinct collagens. Mol Cell Biochem 1976;13(3): 165-92.

${ }^{8}$ Bornstein P, Sage H. Structurally distinct collagen types. Annu Rev Biochem 1980;49:957-1003.

Requests for reprints to: Dr DN Challacombe, Consultant Paediatrician, Somerset Children's Research Unit, Taunton and Somerset Hospital, Musgrove Park Branch, Taunton TA1 5DA, England. 
The Manchester course on gynaecological and obstetrical pathology

Monday 7 April to Friday 11 April 1986 at the Department of Pathology, St Mary's Hospital, Manchester.

Apply to Professor H Fox, Department of Pathology, Stopford Building, University of Manchester, Manchester M13 9PT.

\section{Symposium on DNA technology}

There will be a symposium at the Royal College of Pathologists on the applications of DNA technology to pathology, on Thursday March 6 and Friday 71986 , at the Royal College of Physicians, London. Further particulars can be obtained from Miss Christine Peddle, Scientific Meetings Officer, Royal College of Pathologists, 2 Carlton House Terrace, London SW1.

\section{Association of Clinical Pathologists Research award (amended rules)}

1 Council of the Association has decided to award an annual prize of $£ 250$ for the best paper presented by a member under the age of 35 years at the autumn general meeting of the Association.

2 The prize will be awarded by council on the recommendation of a panel of adjudicators from the education committee at their January meeting following presentations. Criteria for assessing the merit of entries will include originality, scientific importance, and lucidity of presentation. The award will be made at the next spring general meeting of the Association.

3 These papers must be presented by members or junior members, 35 years of age or under in the year of entry. A paper may have been read at a meeting but must not have appeared in print before the last date for receipt of entries (rule 5).

4 Work that has been carried out by more than one person must be accompanied by a statement of the extent of the contribution to the work made by the member presenting the paper. Joint work is acceptable provided that the substantial part of the work was carried out by the candidate for the prize. Others involved in the project-for example, a supervisor, must indicate their approval in writing.

5 To give the papers of candidates for the prize a degree of priority on the programmes of meetings a member presenting a paper for consideration for the prize must give written notice to that effect to the Meetings Secretary. The last date for receipt of this notice will be 1st May preceding the autumn meeting. An abstract (about 250 words in length) of the paper must be sent with the notice.

Problems in tumour pathology, Friday 18 April 1986, Christie Hospital, Manchester

Designed for consultants and trainees in histopathology the course will address problems in diagnostic tumour pathology in the form of a slide seminar. A set of slides and case histories will be circulated beforehand.

The course is limited to 25 participants.

Course fee is $£ 15$ (includes slides, coffee, lunch, and tea).

For further information and application apply to: Dr M Harris, Department of Pathology, Christie Hospital, Withington, Manchester M20 9BX.

A monthly slide seminar on tumour pathology is also run at the Christie Hospital, Manchester. This is particularly suitable for trainees. Enquiries to Dr M Harris.

Advanced haematology course, Monday 24 to Thursday 27 March 1986, Somerville College, Oxford

Topics will include: molecular haematology applied to congenital anaemia and haematological malignancy; haemostatic disorders; principles of chemotherapy; bone marrow transplantation and blood transfusion.

Course fee is $£ 135$. For further details and application contact: Dr FG Bolton, Department of Haematology, Level 4, John Radcliffe Hospital, Headington, Oxford OX39DU.

Notices of other courses organised by the Association of Clinical Pathologists:

Seminar on cardiovascular pathology, Thursday 6, Friday 7 March 1986 at the National Heart Hospital, London.
Apply to: EGJ Olsen, Department of Pathology, National Heart Hospital, Westmoreland Street, London W1M 8B.

Histopathology of the skin, Monday 17 to Friday 21 March 1986 at the University of Glasgow.

Apply to: The Postgraduate Medical Office, University of Glasgow, Glasgow G128QQ.

Postgraduate course in gynecological and obstetric pathology with clinical correlation, April 14-18 1986

The Departments of Pathology, of the Massachusettes General Hospital and Brigham and Women's Hospital, Harvard Medical School will present a postgraduate course in gynecological and obstetric pathology under the direction of Drs RE Scully, RH Young, and Shirley G Driscoll.

This course is designed for pathologists and obstetrician gynecologists at houseman and practitioner levels, providing a comprehensive review of gynecological and obstetric pathology, with emphasis on morphological diagnostic features and clinicopathological correlation, including management. Special attention will be paid to recent advances and newly recognised entities. Instruction will be primarily by lecture with case presentations, and discussion periods in addition. Each participant will receive a comprehensive course syllabus.

The fee for the course is $\$ 495.00$. For further information contact: Department of Continuing Education, Harvard Medical School, 25 Shattuck Street, Boston, MA 02115 (Telephone: 617-732-1526).

\section{ACP Locum Bureau}

The Association of Clinical Pathologists runs a locum bureau for consultant pathologists.

Applicants with the MRC Path who would like to do locums and anyone requiring a locum should contact Dr David Melcher, Histopathology Department, Sussex County Hospital, Eastern Road, Brighton BN2 5BE.

\section{Correction}

On page 1388 of the December issue under the heading of ORGAN CULTURE the word proprietary should read Fungizone. 